\title{
Anatomical Patterns of the Nasopalatine Canal and Incisive Foramen in an African Setting - a Cross-sectional Study
}

Krishan Sarna ( $\sim$ krishnasarna@gmail.com )

University of Nairobi School of Medicine https://orcid.org/0000-0003-4369-093X

Merna Akram Estreed

University of Nairobi School of Medicine

Khushboo Jayant Sonigra

University of Nairobi School of Medicine

Thomas Amuti

University of Nairobi School of Medicine

Florence Opondo

University of Nairobi School of Medicine

Martin Kamau

University of Nairobi School of Medicine

Wei Cheong Ngeow

University of Malaya Faculty of Medicine

\section{Research Article}

Keywords: Nasopalatine canal, Incisive foramen, Maxillary bone, Dental implants, Radiology, CBCT

Posted Date: December 10th, 2021

DOI: https://doi.org/10.21203/rs.3.rs-1146197/v1

License: @ (i) This work is licensed under a Creative Commons Attribution 4.0 International License. Read Full License 


\section{Abstract}

Purpose: Surgical procedures revolving around the anterior maxilla are of great interest due to their debilitating facial aesthetics and nerve injury effects if complications arise. Hence, sufficient knowledge concerning the morphology and morphometry of the nasopalatine canal (NPC) and incisive foramen (IF) is necessary to prevent such complications from arising.

Materials and Methods: Measurements of the NPC and the IF were carried out on 150 CBCT scans. The maxillary bone thickness anterior to the NPC was measured at 3 levels. Independent $t$-test and chi-square test were performed to determine the presence of sexual dimorphism.

Results: The presence of one Stenson's foramen was most prevalent. The mean length of NPC was $13.21 \pm 3.25 \mathrm{~mm}$ with significantly longer canals in males. The most prevalent shape of NPC was cylindrical in sagittal view and a single canal in coronal view. The mean angulation of NPC was $118.42^{\circ}$ to the horizontal plane. The average dimensions of the IF were $3.53 \mathrm{~mm}$ and $3.07 \mathrm{~mm}$ in the anteroposterior and mediolateral diameter respectively while the most common shape was round. The anterior maxillary bone was thicker in males and generally reduced in thickness from the anterior nasal spine superiorly towards the alveolar crest inferiorly.

Conclusion: This study highlights the anatomical characteristics of the NPC and IF, with significant sexual dimorphism observed regarding the number of Stenson's foramina, length of NPC, shapes of the NPC and IF as well as alveolar bone thickness anterior to NPC.

\section{Introduction}

The human skull is perforated by multiple canals and foramina, with many western works of literature reporting their various morphologic and morphometric measurements. However, literature concerning Africans is scarce despite the huge and diverse population. Among those available are studies on the infraorbital foramen, zygomatic foramen, and mental foramen which report significant racial differences $[15,24,29,30]$. Zhang et al. reported that the infraorbital foramen was smaller and exited more laterally, with a lower proportion of accessory foramina in an African American population compared with a Caucasian population. The former was also reported to exhibit a distinct type of infraorbital foramen besides having more zygomatic foramina $[29,30]$. On the other hand, the South Africans and Tanzanians have been reported to have a mental foramen located at the second premolar, while Zambian's most common position was between the second premolar and first molar $[15,24]$. These morphologic differences should be considered during surgical planning and anesthetic procedures to avoid neurovascular complications.

Currently, only one study has been dedicated to assessing the Incisive Foramen (IF) in a Kenyan population however, the information reported was restricted to its shape and diameter [11]. None have been dedicated to the Nasopalatine Canal (NPC) itself, a bony tunnel located posteromedial to the maxillary central incisors in the palatal midline which establishes a connection between the floor of the nasal cavity and the roof of the oral cavity. It commences superiorly from the foramina of Stenson (usually two in number) leading into the respective canals that fuse inferiorly to form a single canal - the NPC, which terminates inferiorly at the IF. The canal transmits the nasopalatine nerve and sphenopalatine artery accompanied by adipose tissue and some minor salivary glands [16].

The anatomy of the NPC and IF described above has been shown to exhibit considerable anatomical variation of both morphology and morphometry [13]. Some variations described by various authors include aberrant numbers of Stenson's foramina, deviations in mean length and width of the NPC, dimensions of the IF, the morphology of the NPC in both sagittal and coronal sections as well as variant shapes of the IF [2]. Furthermore, the maxillary bone located anterior to the NPC has previously been described as flat, concave, or convex in shape and is of vital consideration during implant fixture selection and placement. Understanding these characteristics is crucial while trying to distinguish between normal variations and 
pathological conditions as well as making preventive measures before carrying out surgical procedures in this region. Potential for several negative outcomes exists as a result of encroachment into the NPC including hemorrhage from the sphenopalatine artery, sensory deficit, failure of osseointegration, and implant rejection thus emphasizing the importance of having a thorough knowledge of possible anatomical variations within this region [20].

Due to the scarcity of relevant information in Africans, this study aims to describe the morphology and morphometry of the NPC and IF using 3 dimensional Cone Beam Computed Tomography (CBCT) scans obtained from a Kenyan adult population. Additionally, sexual dimorphism regarding the shape and size of the NPC, IF and the anterior maxillary bone were explored.

\section{Materials And Methods}

This radiological study was approved by the Kenyatta National Hospital - University of Nairobi Ethics and Research Committee (KNH-UON ERC), protocol number UP166/03/2021. In this retrospective study, 150 archived CBCT radiographs of Kenyan adult patients comprising of 80 males and 70 females between ages 21-35 were obtained from the Dental And Maxillofacial Imaging Center (DAMIC), Nairobi, Kenya using a CS 9300 3D digital imaging system (Carestream Dental LLC, Atlanta, GA, USA). The images were obtained at $90 \mathrm{kV}, 10 \mathrm{~mA}$ with a voxel size of $76.5 \mu \mathrm{m}^{3}$ and a $200 \mu \mathrm{m}$ image resolution. All images were viewed with a 19 inch LCD monitor (HP L1910, Hewlett-Packard Development Co., Palo Alto, CA, USA) with $1280 \times 1024$ pixel resolution. The CS Imaging software was used during the analysis of the radiographs (Carestream Health Inc., St. Rochester, NY, USA). The CBCT scans were taken for various diagnostic purposes such as dental implants, implanted teeth, oral pathology, or craniofacial trauma. Inclusion criteria in this study sample were: good quality CBCT maxillary images, absence of atrophy of the maxilla, and absence of any pathologic lesions in the anterior maxilla. Exclusion criteria included the presence of residual roots/impacted teeth, cleft palate, ongoing orthodontic treatment, or having undergone surgery in this region. To assess intra-observer consistency, $20 \%$ of the measurements were re-evaluated and recorded as blinds to the first measurements after 2 weeks. This study was performed following the STROBE initiative.

A detailed description of all landmarks used for morphometric measurements in this study has been provided and summarized in Table 1 and is diagrammatically represented in Figure 1. As of the morphological observations, the shape of the canal was examined in the sagittal section and classified into six groups according to the Etoz and Sisman classification (2014), which included: Tree branch, conical, hourglass, funnel, banana, and cylindrical shapes. In the coronal section, the shape was classified as either single, double, or Y-shaped [8]. The shape of the IF was classified by adding two shapes, the teardrop, and the diamond shape to the original classification by Bahşi et al. (2019) who found the IF to be either round, oval, heart, or triangular in shape [3]. Additionally, the anterior maxillary bone was classified as either concave, convex, or flat. 
Table 1

Description of morphometric measurements and morphological observations performed in the present study

\begin{tabular}{|c|c|c|}
\hline Structure & Parameter & Description \\
\hline \multirow{10}{*}{$\begin{array}{l}\text { Nasopalatine } \\
\text { Canal }\end{array}$} & \multicolumn{2}{|c|}{ Morphometric measurements } \\
\hline & $\begin{array}{l}\text { Number of } \\
\text { Stenson's } \\
\text { foramina }\end{array}$ & Number of foramina found at the level of the nasal fossa $(1,2$ or 3$)$ \\
\hline & $\begin{array}{l}\text { Length of } \\
\text { the NPC }\end{array}$ & $\begin{array}{l}\text { Measured in sagittal section from the floor of the nasal fossa to the level of the incisive } \\
\text { foramen along the long axis of the canal }\end{array}$ \\
\hline & $\begin{array}{l}\text { Antero- } \\
\text { posterior } \\
\text { dimension } \\
\text { of NPC }\end{array}$ & $\begin{array}{l}\text { The inner diameter measured in sagittal sections at } 3 \text { levels: (a) Level of the Stenson's } \\
\text { foramen (b) Mid-point level (c) Level of incisive foramen }\end{array}$ \\
\hline & $\begin{array}{l}\text { Medio- } \\
\text { lateral } \\
\text { dimension } \\
\text { of NPC }\end{array}$ & $\begin{array}{l}\text { The inner diameter measured in coronal sections at } 3 \text { levels: (a) Level of the Stenson's } \\
\text { foramen (b) Mid-point level (c) Level of incisive foramen }\end{array}$ \\
\hline & $\begin{array}{l}\text { Angulation } \\
\text { of NPC }\end{array}$ & $\begin{array}{l}\text { Angulation of canal measured from the horizontal plane to the long axis of the canal } \\
\text { viewed in a sagittal section }\end{array}$ \\
\hline & \multicolumn{2}{|c|}{ Morphologic observations } \\
\hline & $\begin{array}{l}\text { Sagittal } \\
\text { shape of } \\
\text { NPC }\end{array}$ & $\begin{array}{l}\text { Observations made in the sagittal plane and classified as tree branch, conical, } \\
\text { hourglass, funnel, banana or cylindrical }\end{array}$ \\
\hline & $\begin{array}{l}\text { Coronal } \\
\text { shape of } \\
\text { NPC }\end{array}$ & $\begin{array}{l}\text { Observations made in the coronal plane classified as either a single, double or Y- } \\
\text { shaped }\end{array}$ \\
\hline & \multicolumn{2}{|c|}{ Morphometric measurements } \\
\hline \multirow[t]{4}{*}{$\begin{array}{l}\text { Incisive } \\
\text { foramen }\end{array}$} & $\begin{array}{l}\text { Antero- } \\
\text { posterior } \\
\text { diameter }\end{array}$ & $\begin{array}{l}\text { Measurements made on axial sections along its widest point in the antero-posterior } \\
\text { direction }\end{array}$ \\
\hline & $\begin{array}{l}\text { Medio- } \\
\text { lateral } \\
\text { diameter }\end{array}$ & $\begin{array}{l}\text { Measurements made on axial sections along its widest point in the medio-lateral } \\
\text { direction }\end{array}$ \\
\hline & \multicolumn{2}{|c|}{ Morphologic observations } \\
\hline & $\begin{array}{l}\text { Shape of } \\
\text { the IF }\end{array}$ & $\begin{array}{l}\text { Observations made in axial section and classified as round, oval, heart, triangle, tear } \\
\text { drop or diamond }\end{array}$ \\
\hline \multirow{4}{*}{$\begin{array}{l}\text { Maxillary } \\
\text { bone }\end{array}$} & \multicolumn{2}{|c|}{ Morphometric measurements } \\
\hline & $\begin{array}{l}\text { Dimensions } \\
\text { of the } \\
\text { maxillary } \\
\text { bone }\end{array}$ & $\begin{array}{l}\text { Thickness of maxillary bone in sagittal section measured from the buccal wall of NPC } \\
\text { to the outer buccal cortex: (a) at the level of the nasal spine (b) at a level half-way } \\
\text { between the nasal spine and alveolar crest (c) at the level of the alveolar crest }\end{array}$ \\
\hline & $\begin{array}{l}\text { Angulation } \\
\text { of maxillary } \\
\text { bone }\end{array}$ & $\begin{array}{l}\text { Angulation of maxillary bone in sagittal section measured from the horizontal plane } \\
\text { alone the long axis of the bone }\end{array}$ \\
\hline & \multicolumn{2}{|c|}{ Morphologic observations } \\
\hline
\end{tabular}




\begin{tabular}{|lll|}
\hline Structure & Parameter & Description \\
\hline $\begin{array}{l}\text { Shape of } \\
\text { the } \\
\text { maxillary } \\
\text { bone }\end{array}$ & $\begin{array}{l}\text { Observations made on sagittal section regarding shape of the buccal cortex of } \\
\text { maxillary bone classified as either concave, convex or flat }\end{array}$ \\
\hline
\end{tabular}

All qualitative data were assigned numerical values for analysis, consequently, an average value for each measurement was calculated using IBM SPSS Statistics version 27 (IBM Corp, New York, USA) and tabulated. Morphometric data obtained was subjected to an independent $t$-test while morphologic data were subjected to a chi-square test to assess for any sexual dimorphism between the various parameters. A $p$-value of $<0.05$ was considered significant at a $95 \%$ confidence interval. Data were summarized in tables and figures for ease of reference.

\section{Results}

A total of 150 CBCT scans were included in the present study of which 80 were males $(53.3 \%)$ and 70 were females (46.7\%) with an average age of $28.4 \pm 5.5$ years. To eliminate intra-observer and inter-observer bias, initial measurements were performed and compared with measurements taken two weeks later. No significant differences between the results collected by different examiners were found (Independent $t$-test, $p$-value >0.05).

\section{Nasopalatine Canal}

A detailed analysis of the NPC revealed that it often commenced from one Stenson's foramen in $87.9 \%$ of males and $69.2 \%$ of females, while from two foramina in $9.1 \%$ and $30.8 \%$ of males and females respectively. Three foramina were found in $3.0 \%$ of males but none were observed in females (figure 2). There was a statistically significant difference in the number of foramina with respect to gender (Chi-square test, $p$-value $<0.05$ ).

The mean length of the NPC in males was found to be $14.43 \pm 3.27 \mathrm{~mm}$ which was significantly greater than that of the females at $11.98 \pm 3.23 \mathrm{~mm}$ (Independent $t$-test, $p<0.05$ ). The anteroposterior diameter of the NPC in females was greater at all three levels as compared to the males; conversely, the mediolateral diameter of the NPC in males was greater than that of females. These results, however, did not exhibit any sexual dimorphism (Independent $t$-test, $p>0.05$ ). As pertains to the angulation of the NPC, the results show a similar inclination in both genders at $118^{\circ}$ to the horizontal plane (Table 2). 
Table 2

Morphometric measurements of the NPC with standard deviations (SD) and $p$-values for both males and females (*Independent $t$-test, $P<0.05$ )

\begin{tabular}{|c|c|c|c|c|c|}
\hline \multirow[t]{2}{*}{ Parameter } & \multicolumn{4}{|l|}{ Measurements } & \multirow{2}{*}{$\begin{array}{l}P \\
\text { value }\end{array}$} \\
\hline & Level & Male (SD) & Female (SD) & $\begin{array}{l}\text { Combined } \\
\text { (SD) }\end{array}$ & \\
\hline Length of NPC (mm) & - & $14.43(3.27)$ & $11.98(3.23)$ & $13.21(3.25)$ & *0.002 \\
\hline \multirow[t]{3}{*}{$\begin{array}{l}\text { Antero-posterior diameter of NPC } \\
(\mathrm{mm})\end{array}$} & $\begin{array}{l}\text { Stenson's } \\
\text { foramen }\end{array}$ & $3.39(2.01)$ & $3.65(2.77)$ & $3.52(2.39)$ & 0.743 \\
\hline & $\begin{array}{l}\text { Mid-point of } \\
\text { canal }\end{array}$ & $2.36(1.12)$ & $2.62(1.76)$ & $2.49(1.44)$ & 0.467 \\
\hline & Incisive Foramen & $3.03(1.30)$ & $3.38(1.61)$ & $3.21(2.91)$ & 0.322 \\
\hline \multirow[t]{3}{*}{ Medio-lateral diameter of NPC (mm) } & $\begin{array}{l}\text { Stenson's } \\
\text { foramen }\end{array}$ & $4.12(1.09)$ & $3.68(1.24)$ & $3.90(1.17)$ & 0.104 \\
\hline & $\begin{array}{l}\text { Mid-point of } \\
\text { canal }\end{array}$ & $3.03(1.16)$ & $2.74(1.37)$ & $2.89(1.27)$ & 0.343 \\
\hline & Incisive Foramen & $2.96(1.09)$ & $2.65(1.17)$ & $2.81(1.13)$ & 0.256 \\
\hline Angulation of NPC $\left(^{\circ}\right)$ & - & $\begin{array}{l}118.85 \\
(9.08)\end{array}$ & $\begin{array}{l}118.00 \\
(10.05)\end{array}$ & $118.42(9.53)$ & 0.686 \\
\hline
\end{tabular}

Two views were used in the examination of the morphology of the NPC: a sagittal view and a coronal view. In the sagittal view (Figure 3), the most common shape of the NPC for males was cylindrical followed by an hourglass, conical, banana, funnel and tree branch patterns. On the other hand, the most common shape in females was cylindrical as well, followed by funnel, conical, banana, hourglass, and tree branch patterns. In the coronal view (Figure 4), a single canal was the most prevalent for both genders followed by the double canal for males and $\mathrm{Y}$-the shaped canal for the females. The results reveal a statistically significant difference pertaining to the shape of the NPC in both sagittal and coronal views with respect to gender (Chi-square test, $p<0.05$ ).

\section{Incisive foramen}

The morphometry of the IF revealed that the average anteroposterior diameter of the IF on the axial section was found to be $3.46 \pm 1.35 \mathrm{~mm}$ in males and $3.60 \pm 1.15 \mathrm{~mm}$ in females. Additionally, the mediolateral diameter was $2.97 \pm 1.09 \mathrm{~mm}$ and $3.16 \pm 1.08 \mathrm{~mm}$ in males and females respectively, these results did not exhibit any significant sexual dimorphism (Independent $t$-test $p$-value $>0.05$ ).

As pertains morphology of the IF, a wide range of shapes was observed (Figure 5). The most frequently encountered shape in males was the round IF followed by the oval, teardrop, heart, and diamond shapes. No triangular IF was encountered. As for the females, the most common shape was the round IF followed by the oval, heart, teardrop, diamond, and lastly triangular. The shape of the IF exhibited significant sexual dimorphism (Chi-square test $-p<0.05$ ).

\section{Maxillary bone}

The thickness of the maxillary bone anterior to the NPC was measured at three levels; at the nasal spine, at the mid-point, and the alveolar crest (Figure 1). In general, the results reveal that on average males had a thicker maxillary bone at all levels in comparison to females (Table 3). 
Table 3

Dimensions of the maxillary bone at three different levels for both male and female Kenyans (*Independent $t$-test, $p<0.05)$.

\begin{tabular}{|llllll|}
\hline Parameter & \multicolumn{1}{l}{ Gender } & & & & \multirow{2}{*}{$P$-value } \\
\cline { 2 - 6 } & Level & Male (SD) & Female (SD) & Combined (SD) & \\
\hline Dimension of the maxillary bone & Nasal spine & $11.54(3.16)$ & $10.19(3.61)$ & $10.87(3.39)$ & 0.10 \\
\cline { 2 - 6 } & Mid-level & $7.57(1.98)$ & $6.62(2.03)$ & $7.10(2.01)$ & $* 0.04$ \\
\cline { 2 - 6 } & Alveolar crest & $6.70(1.60)$ & $5.89(2.12)$ & $6.30(1.86)$ & 0.08 \\
\hline
\end{tabular}

However, only the mid-point thickness was found to be significantly higher in males (Independent $t$-test, $p<0.05$ ). Lastly, the general trend observed was a reduction in the thickness of bone from the level of the nasal spine to the alveolar crest.

As pertain the shape of the maxillary bone, it was classified as either concave, convex, or flat (Figure 6). The results reveal that the flat shape was most prevalent among males while the concave shape was most prevalent among females. No convex shape was encountered in this study. These results exhibited sexual dimorphism (Chi-square test, $p<0.05$ ). Furthermore, the angulation of the maxillary bone was found to be similar at an average of $116.00^{\circ}$ to the horizontal plane in both males and females.

\section{Discussion}

With the rise of dental awareness and the demand for aesthetically pleasing facial appearances, procedures associated with the anterior maxilla such as the administration of local anesthesia, implantology, palatoplasty, cystectomy of radicular, and nasopalatine duct cysts, and extraction of supernumerary mesiodens have become frequently performed procedures [28]. The NPC and IF are major structures of the pre-maxilla region that must be taken into consideration during planning and when performing any of these procedures. The introduction of CBCT has enabled their detailed 3-dimensional evaluation with a far wider range of possible measurements that can be carried out to better characterize these structures for diagnostic purposes [10].

The current study aims to provide detailed information on the morphology and morphometry of the NPC and IF. It also aims to highlight the sexual dimorphism that may be seen in an African (Kenyan) population, as previously it has been suggested that females are usually more petite, have more gracile cranial and postcranial features, and smaller teeth [17]. This is important because levels of sexual dimorphism have been significantly reduced throughout human evolution.

\section{Morphology and morphometry of the nasopalatine canal}

The findings from the present study reveal that the majority of the canals commenced from a single Stenson's foramen which is in concordance with existing literature from the Sinhalese and Swiss populations. However, this is in contrast to Indian and American population groups where the most prevalent number of Stenson's foramina was reported to be two [4, 12 27]. Furthermore, sexual dimorphism concerning the number of openings was observed in the present study, contrary to the findings of Thakur et al. (2013). Racial differences have been suggested to influence the prevalence of the variations and it is believed that the current findings are unique to the Kenyan population [2, 27].

With regards to the length of the NPC in Kenyans, males were found to have significantly longer NPC compared to females which is consistent with findings from existing literature $[1,12,27]$. The mean length of the canal as noted in our setting $(13.21 \mathrm{~mm})$ is higher than that reported in Sinhalese, Americans, and Iranians [2, 12, 27]. Our values were, however, lower than the Indians' [23] (Table 4). 
Table 4

The NPC dimensions of the Kenyan in comparison with the different populations

\begin{tabular}{|c|c|c|c|c|c|c|c|c|c|}
\hline \multirow[t]{2}{*}{ Author } & \multirow[t]{2}{*}{ Population } & \multirow{2}{*}{$\begin{array}{l}\text { Length } \\
\text { of } \\
\text { NPC } \\
(\mathrm{mm})\end{array}$} & \multicolumn{3}{|c|}{$\begin{array}{l}\text { Antero-posterior diameter of } \\
\text { NPC (mm) }\end{array}$} & \multicolumn{3}{|c|}{$\begin{array}{l}\text { Medio-lateral diameter of NPC } \\
(\mathrm{mm})\end{array}$} & \multirow[t]{2}{*}{$\begin{array}{l}\text { Angulation } \\
\left({ }^{\circ}\right)\end{array}$} \\
\hline & & & $\begin{array}{l}\text { Stenson's } \\
\text { foramen }\end{array}$ & $\begin{array}{l}\text { Mid- } \\
\text { point } \\
\text { of } \\
\text { canal }\end{array}$ & $\begin{array}{l}\text { Incisive } \\
\text { foramen }\end{array}$ & $\begin{array}{l}\text { Stenson's } \\
\text { foramen }\end{array}$ & $\begin{array}{l}\text { Mid- } \\
\text { point } \\
\text { of } \\
\text { canal }\end{array}$ & $\begin{array}{l}\text { Incisive } \\
\text { foramen }\end{array}$ & \\
\hline $\begin{array}{l}\text { Al-Amery et } \\
\text { al., } 2015 \text { [1] }\end{array}$ & Mongoloids & 16.33 & 6.06 & - & 2.80 & 6.08 & - & 3.49 & - \\
\hline $\begin{array}{l}\text { Fernández- } \\
\text { Alonso et } \\
\text { al., } 2014 \text { [9] }\end{array}$ & Spanish & 12.34 & - & - & - & - & - & - & 73.33 \\
\hline $\begin{array}{l}\text { Jayasinghe } \\
\text { et al., } 2020 \\
\text { [12] }\end{array}$ & Sinhalese & 12.14 & 2.85 & 2.37 & 3.03 & - & - & 3.69 & 115.69 \\
\hline $\begin{array}{l}\text { Kajan et al., } \\
2015 \text { [13] }\end{array}$ & Iranian & 12.84 & 3.70 & 2.35 & 3.53 & - & - & - & - \\
\hline $\begin{array}{l}\text { Sekerci et } \\
\text { al., 2014 } \\
\text { [22] }\end{array}$ & Turkish & 10.83 & 2.53 & - & 4.13 & - & - & - & - \\
\hline $\begin{array}{l}\text { Soumya et } \\
\text { al., } 2019 \\
\text { [23] }\end{array}$ & Indians & 18.63 & - & - & 3.12 & - & - & 3.23 & - \\
\hline $\begin{array}{l}\text { Present } \\
\text { study }\end{array}$ & Kenyans & 13.21 & 3.52 & 2.49 & 3.21 & 3.90 & 2.89 & 2.81 & 118.42 \\
\hline
\end{tabular}

The anteroposterior diameter of the NPC at the level of Stenson's foramen (3.52 mm), mid-point of the canal $(2.49 \mathrm{~mm})$, and at the level of the IF $(3.21 \mathrm{~mm})$ were similar to findings in the Turkish and Iranian populations but differed greatly from the Mongoloids and Indian groups [1, 22, 23]. In addition, the mediolateral diameter of the canal was found to be smaller in comparison to all population groups studied, portraying a more slender canal in a mediolateral dimension compared to the anteroposterior dimension in Kenyans. This dimension is favorable for the placement of an implant into the NPC if the need arises [4]. Furthermore, the angulation of the canal $\left(118.42^{\circ}\right)$ in the present study is relatively similar to that reported in Sinhalese and Americans but is greater than the Indians $[2,12,27]$ (Table 4).

The results pertaining to the shape of the NPC in the sagittal view reveal that the majority of Kenyans had a cylindrical canal $(38.89 \%)$ which is a greater prevalence than that observed in Sinhalese and Turkish populations. However, it is less than that reported in the Iranians $[12,13,22]$. The second most common shape in this study was found to be the conical shape (16.67\%) which is similar to that in the Turkish population and significantly higher than that found in the Iranian group $[13,22]$. Both these shapes are favorable for the placement of implants into the anterior maxillary bone. The prevalence of the banana, funnel, hourglass, and tree branch shapes was within the range reported in various population groups (Table 5). 
Table 5

The shape of the NPC (in the sagittal view) of the Kenyan compared with other populations

\begin{tabular}{|c|c|c|c|c|c|c|c|}
\hline \multirow[t]{2}{*}{ Author } & \multirow[t]{2}{*}{ Population } & \multicolumn{6}{|c|}{ Shape of the NPC (Sagittal) (\%) } \\
\hline & & Cylindrical & Banana & Funnel & Hourglass & $\begin{array}{l}\text { Tree } \\
\text { Branch }\end{array}$ & Conical \\
\hline $\begin{array}{l}\text { Fernández-Alonso et al., } 2014 \\
\text { [9] }\end{array}$ & Spanish & 48.20 & 0.40 & 20.50 & 30.80 & - & - \\
\hline Jayasinghe et al., 2020 [12] & Sinhalese & 18 & - & 38 & 26 & - & - \\
\hline Kajan et al., 2015 [13] & Iranian & 57.60 & 1.50 & 15.20 & 2.00 & - & 4.50 \\
\hline Sekerci et al., 2014 [22] & Turkish & 15.20 & 19.60 & 26.90 & 15.80 & 6.20 & 16.3 \\
\hline Present study & Kenyans & 38.89 & 11.11 & 15.28 & 15.28 & 2.78 & 16.67 \\
\hline
\end{tabular}

Examination in a coronal view revealed that a significant proportion was found to be of the single canal shape (75.0\%) which is greater than findings in Iranian, Spanish, Turkish, and Swiss populations [9, 13, 22, 25] (Table 6). The prevalence of double canal $(11.11 \%)$, however, is greater than most population groups. On the other hand, the Y-shaped canal was found to have the least prevalence in comparison to any of the population groups. These double canals may result in insufficient anesthesia following the infiltration of local anaesthesic agents as the separating bone between them may hinder the diffusion of the solution to the adjacent canal.

Table 6

The shape of the NPC (in the coronal view) of the Kenyan compared with other populations

\begin{tabular}{|lllll|}
\hline \multirow{2}{*}{ Author } & Population & \multicolumn{3}{c|}{ Shape of the NPC (Coronal) (\%) } \\
\cline { 3 - 5 } & & Single & Double & Y-shaped \\
\hline Fernández-Alonso et al., 2014 [9] & Spanish & 41.10 & 10.30 & 42.40 \\
\hline Kajan et al., 2015 [13] & Iranian & 43.52 & 9.97 & 46.51 \\
\hline Sekerci et al., 2014 [22] & Turkish & 61.41 & 9.78 & 28.80 \\
\hline Suter et al., 2016 [25] & Swiss & 39.30 & 2.60 & 58.20 \\
\hline Present study & Kenyans & 75.00 & $\mathbf{1 1 . 1 1}$ & $\mathbf{1 3 . 8 9}$ \\
\hline
\end{tabular}

\section{Morphology and morphometry of the incisive foramen}

The IF and its overlying incisive papilla are important landmarks in clinical practice. The relationship between the incisive papilla and the maxillary anterior teeth is used for the construction of the maxillary complete denture, and this exact relationship has been reported among Kenyans of African descent [19]. In addition, the IF serves as an important point at which the descending palatine artery may be compressed and consequently embolized to control severe epistaxis [5]. Moreover, the NPC and IF form an integral part of the Kernahan ' $Y$ ' classification system used in grading the severity of submucosal cleft lip and palate, further highlighting the significance of its anatomy [14].

The average dimensions of the IF in the present study were $3.53 \mathrm{~mm}$ and $3.07 \mathrm{~mm}$ in the anteroposterior and mediolateral diameter respectively. This is comparable to dimensions found in Indians and Belgians and is similar to that reported by Hassanali \& Mwaniki (1984) [11, 27]. However, Hassanali \& Mwaniki also reported that the diameter tends to be $>0.4 \mathrm{~cm}$ in 
$20 \%$ of cases with round foramen while the remaining $80 \%$ of IF were cone-shaped [11]. Their findings are in contrast to that observed in the current study, where a majority of the IF was noted to be round (33.30\%). This finding is in keeping with the Turkish and Iranian population groups. However, a study by Nikkerdar et al. (2018) revealed that the majority of IF's were heart-shaped $[3,18,22,26,27]$. Our study also reveals high numbers of diamond, teardrop, and triangle shapes in comparison to other groups. A pathological condition such as the nasopalatine duct cyst should be suspected if the diameter of the IF exceeds $6.0 \mathrm{~mm}$. In the present study, the diameter of the IF was found to range between $1.50 \mathrm{~mm}$ to $5.95 \mathrm{~mm}$ which is in accordance with previously accepted norms (Table 7).

Table 7

The shape of the IF of the Kenyan compared with other populations

\begin{tabular}{|c|c|c|c|c|c|c|c|}
\hline \multirow[t]{2}{*}{ Author } & \multirow[t]{2}{*}{ Population } & \multicolumn{6}{|c|}{ Shape of the IF (\%) } \\
\hline & & Diamond & Heart & Oval & Round & Tear drop & Triangle \\
\hline Bahşi et al., 2018 [3] & Turkish & - & 20.7 & 16.0 & 62.7 & - & 0.7 \\
\hline Nikkerdar et al., 2018 [18] & Iran & - & 46.3 & 10.7 & 33.0 & - & - \\
\hline Sekerci et al., 2014 [22] & Turkish & - & 30.16 & 26.19 & 43.65 & - & - \\
\hline Telebian et al., 2018 [26] & Iran & - & 8.33 & 25 & 58.34 & - & - \\
\hline Present study & Kenyan & 8.33 & 18.06 & 23.61 & 33.33 & 15.28 & 1.39 \\
\hline
\end{tabular}

\section{Morphology and morphometry of the maxillary bone}

The location, shape, and orientation of the NPC need to be evaluated before anterior implant placement, of which the above results are valuable as they provide a baseline for the African Kenyan. This is important especially in cases where a screwretained implant is indicated as its insertion is usually more palatally placed. Equally important is the assessment of the adjacent anterior maxillary bone thickness. One study reported a significant difference in alveolar ridge thickness between the African Americans and Caucasians, with the former exhibiting thinner ridges at the apex for both the central and lateral incisors [21]. Similar to that reported by numerous authors, the bony dimensions demonstrated increment from the region of the alveolar crest to the level of the nasal spine. Males generally had a thicker bone in comparison to females hence, females may require more precautions during implant insertion to avoid perforation of the NPC or buccal cortex, especially in the mid canal region. Alkanderi et al. have shown in their virtual implant placement study that the most perforations occurred in the middle third of the implant [2]. Chan et al. reported that buccal bone fenestrations would occur in approximately $20 \%$ of cases, most commonly in the apical third of the implant if an implant is placed following the axis of its restoration [6]. Because of this, the size of the implant fixtures chosen may be reduced because it is impossible to graft a perforation to the NPC unless the whole NPC is obliterated. The choice of treatment is to immediately insert the implant into the NPC following removal of soft tissue contents and placement of bone graft [20].

Recently, it has been reported that cylindrical (round) canals with a large incisive canal diameter have a smaller alveolar ridge dimension at the apical part. Fortunately, this is not the case for the African Kenyans as they showed sufficient bone due to their average-sized canals (Table 4). In addition, they have a more slender canal in a mediolateral dimension compared to the anteroposterior dimension. In fact, at the mid-point between the nasal spine and alveolar crest (i.e. approximately at the same level as the apical part of the implant), the bone was thicker $(7.10 \mathrm{~mm})$ than that of the mongoloids and Indians [1, 23]. However, at the region of the alveolar crest, the maxillary bone was thinner in comparison to all population groups except for the Turkish [22] (Table 8). So, dehiscence instead of fenestration may be an issue for the African Kenyan. This fact, coupled with the proximity to the NPC described above warrants consideration for the use of non-regular size conical-type (tapered) implant fixtures. 
Table 8

The maxillary bone thicknesses of Kenyan compared with different populations

\begin{tabular}{|lllll|}
\hline \multirow{2}{*}{ Author } & Population & \multicolumn{3}{c|}{ Maxillary bone thickness (mm) } \\
\cline { 3 - 5 } & & Nasal spine & Mid-level & Alveolar crest \\
\hline Al-Amery et al., 2015 [1] & Mongoloids & 10.75 & 6.31 & 7.63 \\
\hline Soumya et al., 2019 [23] & Indians & - & 6.32 & - \\
\hline Kajan et al., 2015 [13] & Iranians & 8.49 & - & 7.05 \\
\hline Sekerci et al., 2014 [22] & Turkish & 6.37 & - & 6.01 \\
\hline Present study & Kenyans & 10.87 & 7.10 & 6.30 \\
\hline
\end{tabular}

Lastly, the results show that at the nasal spine, the maxillary bone was thicker $(10.87 \mathrm{~mm})$ than other population groups such as the mongoloids, Iranians, and the Turkish groups; it thus may be useful as a bone graft donor site $[1,7,13,20,22]$.

With regards to the shape of the maxillary bone, the majority of cases were found to be flat in males and concave in females. This data is scarce in literature therefore little comparison can be made. This finding concurs with the alveolar bone measurements observed at 3 levels of NPC. Therefore, clinicians should be vigilant during implant placement in women due to the concave shape of the bone, which has an increased risk of fenestration. The clinician may need to raise a flap when performing this surgery and shall be ready to graft this perforation when the need arises. Lastly, the angulations of the NPC and the maxillary bone were found to be $118.42^{\circ}$ and $116.00^{\circ}$ revealing that they are relatively parallel to one another, thus an implant can be inserted along the long axis of the bone.

In summary, this study provides a detailed and comprehensive analysis of the NPC and associated structures in the Kenyan population. The information obtained may be used for benchmarking, as clinically it has been reported that the increase in NPC dimensions or the presence of the bulging signs may be indicative of the presence of a nasopalatine duct cyst or the results of dentoalveolar injury to the anterior maxilla [25]. Any deviation from the norm thus necessitates further investigations.

\section{Conclusion}

The results of the present study highlight the prevalence of the anatomic variability concerning multiple aspects of the NPC and IF in a selected Kenyan population. This study highlights their anatomical characteristics, with significant sexual dimorphism seen on the number of Stenson's foramen, length of NPC, and shapes of NPC, IF and alveolar bone anterior to NPC. Kenyan males are more likely to present with one Stenson's foramen and longer NPC, while their female counterparts may have narrower mid-level alveolar bone anterior to the NPC. Kenyan females appear to have more Stenson's foramina with a variety of shapes, and similar variation is observed for the shape of their IF. A significant percentage of them also presented with funnel shape and Y-shaped NPC.

\section{Limitations And Recommendations}

One of the limitations of this study was the reduced sample size due to the strict inclusion and exclusion criteria that were employed. Further studies incorporating a larger sample size should be performed that could also investigate variations of the NPC and IF concerning particular races within the Kenyan population. In addition, additional morphologic and morphometric parameters can be used to better characterize the anterior maxillary region.

\section{Declarations}

Page $11 / 19$ 


\section{CONFLICT OF INTEREST}

The authors of this manuscript have no conflict of interest to declare.

\section{AUTHOR CONTRIBUTION}

K Sarna: Project development, data collection, manuscript writing and edition, revision of the manuscript

MA Estreed: Data collection, manuscript writing, and edition, revision of the manuscript

KJ Sonigra: Data collection, data analysis, manuscript writing and edition, revision of the manuscript

T Amuti: Data collection, manuscript writing, and edition, revision of the manuscript

F Opondo: Manuscript writing and edition, revision of the manuscript, supervision of the study

M Kamau: Manuscript writing and edition, revision of the manuscript, supervision of the study

WC Ngeow: Project development, manuscript writing and edition, revision of the manuscript, supervision of the study

\section{ACKNOWLEDGEMENTS}

The authors express their sincere appreciation to all who took part in this study. No sources of funding were received for this research.

\section{STATEMENTS AND DECLARATIONS}

The authors declare no conflict of interest.

\section{References}

1. Al-Amery, S. M., Nambiar, P., Jamaludin, M., John, J., \& Ngeow, W. C. (2015). Cone Beam Computed Tomography Assessment of the Maxillary Incisive Canal and Foramen: Considerations of Anatomical Variations When Placing Immediate Implants. PLOS ONE, 10(2), e0117251. https://doi.org/10.1371/journal.pone.0117251

2. Alkanderi, A., Al Sakka, Y., Koticha, T., Li, J., Masood, F., \& Suárez-López del Amo, F. (2020). Incidence of nasopalatine canal perforation in relation to virtual implant placement: A cone beam computed tomography study. Clinical Implant Dentistry and Related Research, 22(1), 77-83. https://doi.org/10.1111/cid.12852

3. Bahşi, I., Orhan, M., Kervancıoğlu, P., Yalçın, E. D., \& Aktan, A. M. (2019). Anatomical evaluation of nasopalatine canal on cone beam computed tomography images. Folia Morphologica, 78(1), 153-162.

https://doi.org/10.5603/FM.a2018.0062

4. Bornstein, M. M., Balsiger, R., Sendi, P., \& von Arx, T. (2011). Morphology of the nasopalatine canal and dental implant surgery: A radiographic analysis of 100 consecutive patients using limited cone-beam computed tomography: Nasopalatine canal and dental implant surgery. Clinical Oral Implants Research, 22(3), 295-301. https://doi.org/10.1111/j.1600-0501.2010.02010.x

5. Butrymowicz, A., Weisstuch, A., Zhao, A., Agarwal, J., \& Pinheiro-Neto, C. D. (2016). Endoscopic endonasal greater palatine artery cauterization at the incisive foramen for control of anterior epistaxis: Cautery of Greater Palatine Artery for Anterior Bleeds. The Laryngoscope, 126(5), 1033-1038. https://doi.org/10.1002/lary.25677

6. Chan, H.L.; Garaicoa, P.C.; Suarez, F.; Monje, A.; Benavides, E.; Oh, T.J.; Wang, H.L. Incidence of implant buccal plate fenestration in the esthetic zone: A cone beam computed tomography study. Int. J. Oral Maxillofac. Implants 2014, 29, $171-177$

Page $12 / 19$ 
7. Cho YS, Hwang KG, Park CJ. Postoperative effects of anterior nasal spine bone harvesting on overall nasal shape. Clin Oral Implants Res. 2013 Jun;24(6):618-22. doi: 10.1111/j.1600-0501.2012.02428.x

8. Etoz, M., \& Sisman, Y. (2014). Evaluation of the nasopalatine canal and variations with cone-beam computed tomography. Surgical and Radiologic Anatomy, 36(8), 805-812. https://doi.org/10.1007/s00276-014-1259-9

9. Fernández-Alonso, A., Suárez-Quintanilla, J. A., Muinelo-Lorenzo, J., Bornstein, M. M., Blanco-Carrión, A., \& SuárezCunqueiro, M. M. (2014). Three-dimensional study of nasopalatine canal morphology: A descriptive retrospective analysis using cone-beam computed tomography. Surgical and Radiologic Anatomy, 36(9), 895-905. https://doi.org/10.1007/s00276-014-1297-3

10. Harris, D., Buser, D., Dula, K., Gröndahl, K., Harris, D., Jacobs, R., Lekholm, U., Nakielny, R., Van Steenberghe, D., \& Van Der Stelt, P. (2002). E.A.O. Guidelines for the use of Diagnostic Imaging in Implant Dentistry: A consensus workshop organized by the European Association for Osseointegration in Trinity College Dublin. Clinical Oral Implants Research, 13(5), 566-570. https://doi.org/10.1034/j.1600-0501.2002.130518.x

11. Hassanali, J., \& Mwaniki, D. (1984). Palatal analysis and osteology of the hard palate of the Kenyan African skulls. The Anatomical Record, 209(2), 273-280. https://doi.org/10.1002/ar.1092090213

12. Jayasinghe, R. M., Hettiarachchi, P. V. K. S., Fonseka, M. C. N., Nanayakkara, D., \& Jayasighe, R. D. (2020). Morphometric analysis of nasopalatine foramen in Sri Lankan population using CBCT. Journal of Oral Biology and Craniofacial Research, 10(2), 238-240. https://doi.org/10.1016/j.jobcr.2019.11.002

13. Kajan, Z., Kia, J., Motevasseli, S., \& Rezaian, S. (2015). Evaluation of the nasopalatine canal with cone-beam computed tomography in an Iranian population. Dental Research Journal, 12(1), 14. https://doi.org/10.4103/1735-3327.150289

14. Khan, M., Ullah, H., Naz, S., Iqbal, T., Ullah, T., Tahir, M., \& Ullah, O. (2013). A revised classification of the cleft lip and palate. Canadian Journal of Plastic Surgery, 21(1), 48-50 https://doi.org/10.1177/229255031302100102

15. McKay, C., Tchokonte-Nana, V., \& Mbajiorgu, E. F. (2018). The Mental Foramen in Dry Human Mandibles of Adult South Africans: An Anatomical Study. International Journal of Morphology, 36(4), 1361-1367.

https://doi.org/10.4067/S0717-95022018000401361

16. Mishra, R., Thimmarasa, V., Jaju, P., Mishra, R., \& Shrivastava, A. (2017). Influence of gender and age on nasopalatine canal: A cone-beam computed tomography study. Journal of Dental Implants, 7(1), 15. https://doi.org/10.4103/jdi.jdi_15_17

17. Nikitovic, D. (2018). Sexual dimorphism (humans). In W. Trevathan, M. Cartmill, D. Dufour, C. Larsen, D. ORourke, K. Rosenberg, \& K. Strier (Eds.), The International Encyclopedia of Biological Anthropology (pp. 1-4). John Wiley \& Sons, Inc. https://doi.org/10.1002/9781118584538.ieba0443

18. Nikkerdar, N., Golshah, A., Norouzi, M., \& Falah-Kooshki, S. (2020). Incidence and Anatomical Properties of Retromolar Canal in an Iranian Population: A Cone-Beam Computed Tomography Study. International journal of dentistry, 2020, 9178973. https://doi.org/10.1155/2020/9178973

19. Ogada, C.N., Mutave, R.J., 2017. Incisive papilla and positions of maxillary anterior teeth among Kenyans of African descent. East African Medical Journal. 94(5):385-390

20. Peñarrocha, D., Candel, E., Guirado, J. L. C., Canullo, L., \& Peñarrocha, M. (2014). Implants Placed in the Nasopalatine Canal to Rehabilitate Severely Atrophic Maxillae: A Retrospective Study With Long Follow-up. Journal of Oral Implantology, 40(6), 699-706. https://doi.org/10.1563/AAID-JOI-D-12-00145

21. Renaud, L., Gandhi, V., West, C., Gudhimella, S., \& Janakiraman, N. (2021). Comparison of anterior maxillary and mandibular alveolar parameters in African American and Caucasian women: A retrospective pilot study. Imaging science in dentistry, 51(2), 175-185. https://doi.org/10.5624/isd.20200323

22. Sekerci, A. E., Buyuk, S. K., \& Cantekin, K. (2014). Cone-beam computed tomographic analysis of the morphological characterization of the nasopalatine canal in a pediatric population. Surgical and Radiologic Anatomy, 36(9), 925932. https://doi.org/10.1007/s00276-014-1271-0

Page 13/19 
23. Soumya, P., Koppolu, P., Pathakota, K. R., \& Chappidi, V. (2019). Maxillary Incisive Canal Characteristics: A Radiographic Study Using Cone Beam Computerized Tomography. Radiology Research and Practice, 2019, 1-5. https://doi.org/10.1155/2019/6151253

24. Subramanian, B., Anthony, S. N., Mubbunu, L., Hachombwa, C., Mlawa, M. S., Majambo, M. M., \& Sasi, R. M. (2019). Anthropometrics Analysis of Mental Foramen and Accessory Mental Foramen in Zambian Adult Human Mandibles. The Scientific World Journal, 2019, 1-11. https://doi.org/10.1155/2019/9093474

25. Suter, V. G. A., Jacobs, R., Brücker, M. R., Furher, A., Frank, J., von Arx, T., \& Bornstein, M. M. (2016). Evaluation of a possible association between a history of dentoalveolar injury and the shape and size of the nasopalatine canal. Clinical Oral Investigations, 20(3), 553-561. https://doi.org/10.1007/s00784-015-1548-7

26. Talebian, M., Etemadi, S., Seimareh, KA., Talebian, MH., Seimareh, MA., Sadeghian, R. (2018). Morphological and anatomical assessment of the nasopalatine canal in edentulous patients using cone beam computed tomography. Revista publicando, 5(16):494-502

27. Thakur, A. R., Burde, K., Guttal, K., \& Naikmasur, V. G. (2013). Anatomy and morphology of the nasopalatine canal using cone-beam computed tomography. Imaging science in dentistry, 43(4), 273-281.

https://doi.org/10.5624/isd.2013.43.4.273

28. Tomaszewska, I. M., Popieluszko, P., Tomaszewski, K. A., \& Walocha, J. A. (2019). Anatomy and Variations of the Incisive Foramen. In J. Iwanaga \& R. S. Tubbs (Eds.), Anatomical Variations in Clinical Dentistry (pp. 117-123). Springer International Publishing. https://doi.org/10.1007/978-3-319-97961-8_11

29. Zhang, K. R., Blandford, A. D., Hwang, C. J., \& Perry, J. D. (2019). Anatomic Variations of the Infraorbital Foramen in Caucasian Versus African American Skulls. Ophthalmic Plastic \& Reconstructive Surgery, 35(1), 25-28. https://doi.org/10.1097/IOP.0000000000001126

30. Zhao, Y., Chundury, R. V., Blandford, A. D., \& Perry, J. D. (2018). Anatomical Description of Zygomatic Foramina in African American Skulls. Ophthalmic Plastic \& Reconstructive Surgery, 34(2), 168-171.

https://doi.org/10.1097/IOP.0000000000000905

\section{Figures}




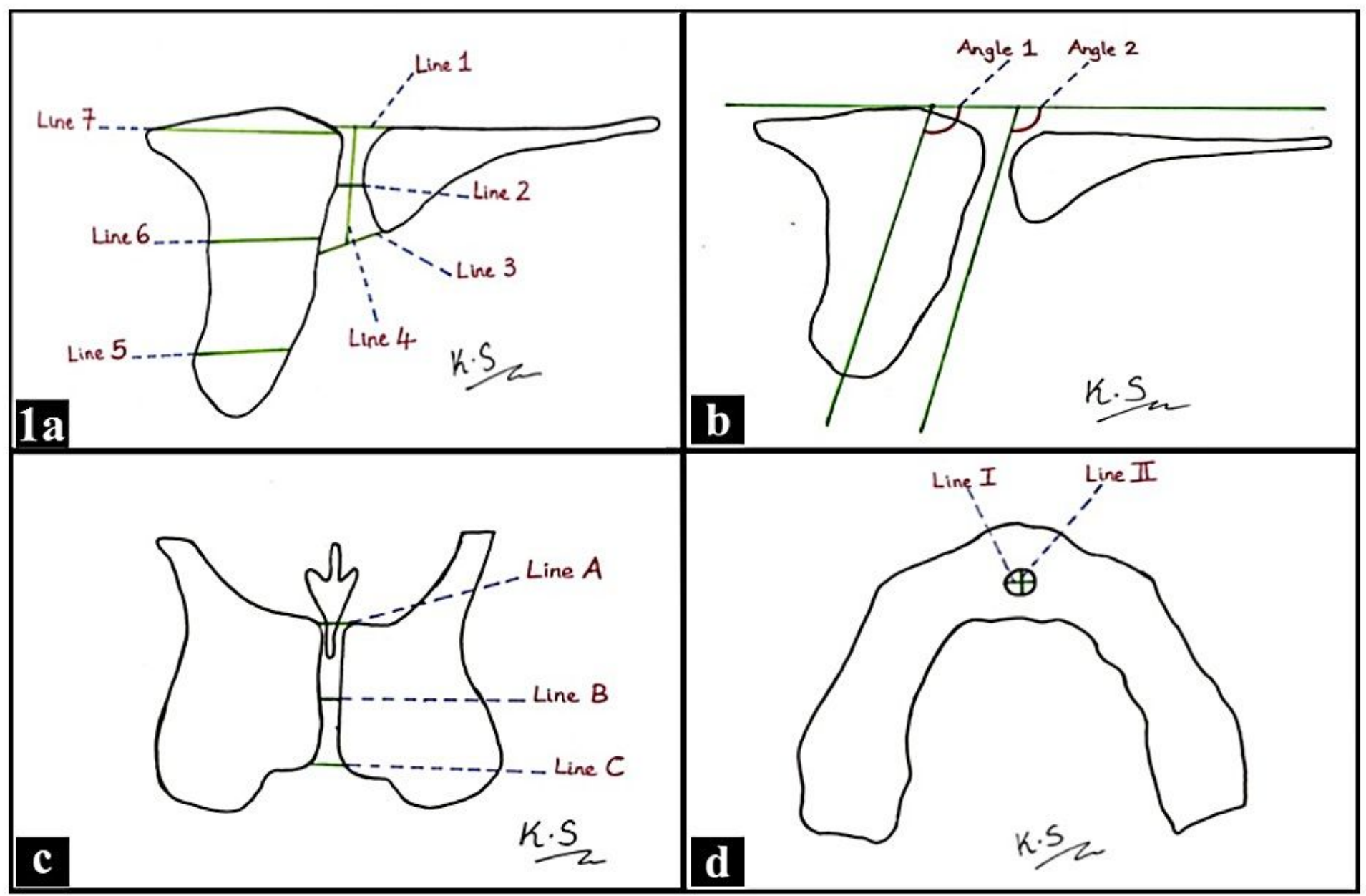

Figure 1

Diagrams showing the various measurements of both the NPC and IF carried out in the present study. 1a: Sagittal view of the NPC, Line 1 - Diameter of the NPC at the level of Stenson's foramen, Line 2 - Diameter at mid-point of NPC, Line 3 Diameter at the level of IF, Line 4 - Length of NPC, Line 5 - Thickness of maxillary bone at the alveolar crest, Line 6 Thickness of maxillary bone at mid-point, Line 7 - Thickness of maxillary bone at nasal spine. 1b: Sagittal view of the NPC, Angle 1 - Angulation of maxillary bone from the horizontal plane, Angle 2 - Angulation of NPC from the horizontal plane. 1c: Coronal view of the NPC, Line A - Diameter of NPC at Stenson's foramen, Line B - Diameter at mid-point of NPC, Line C - Diameter at the level of IF. 1d: Axial view at the level of IF, Line I - Medio-lateral diameter of IF, Line II - Anteroposterior diameter of IF

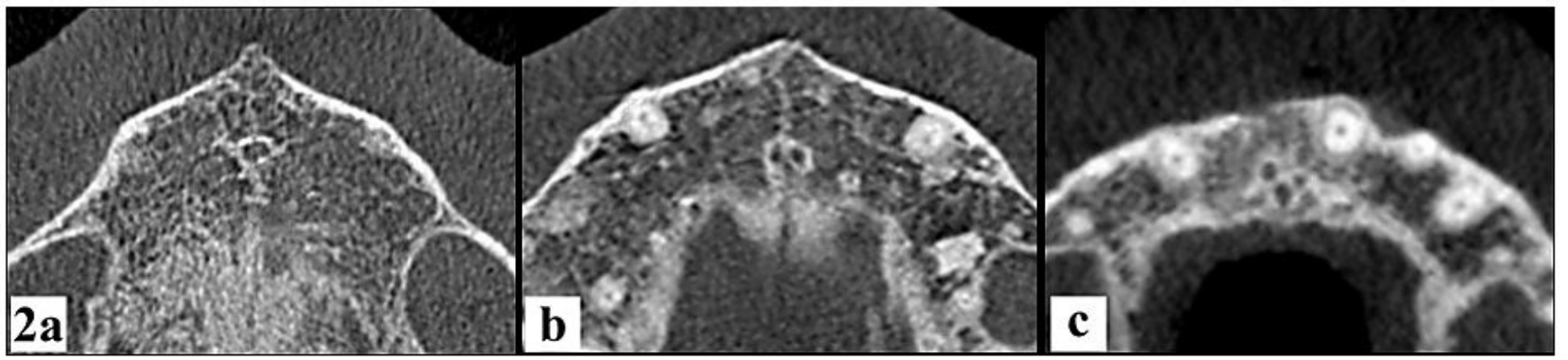

Figure 2

Axial CBCT sections showing the number of Stenson's foramina. 2a: Single foramen 2b: Two foramina 2c: Three foramina 

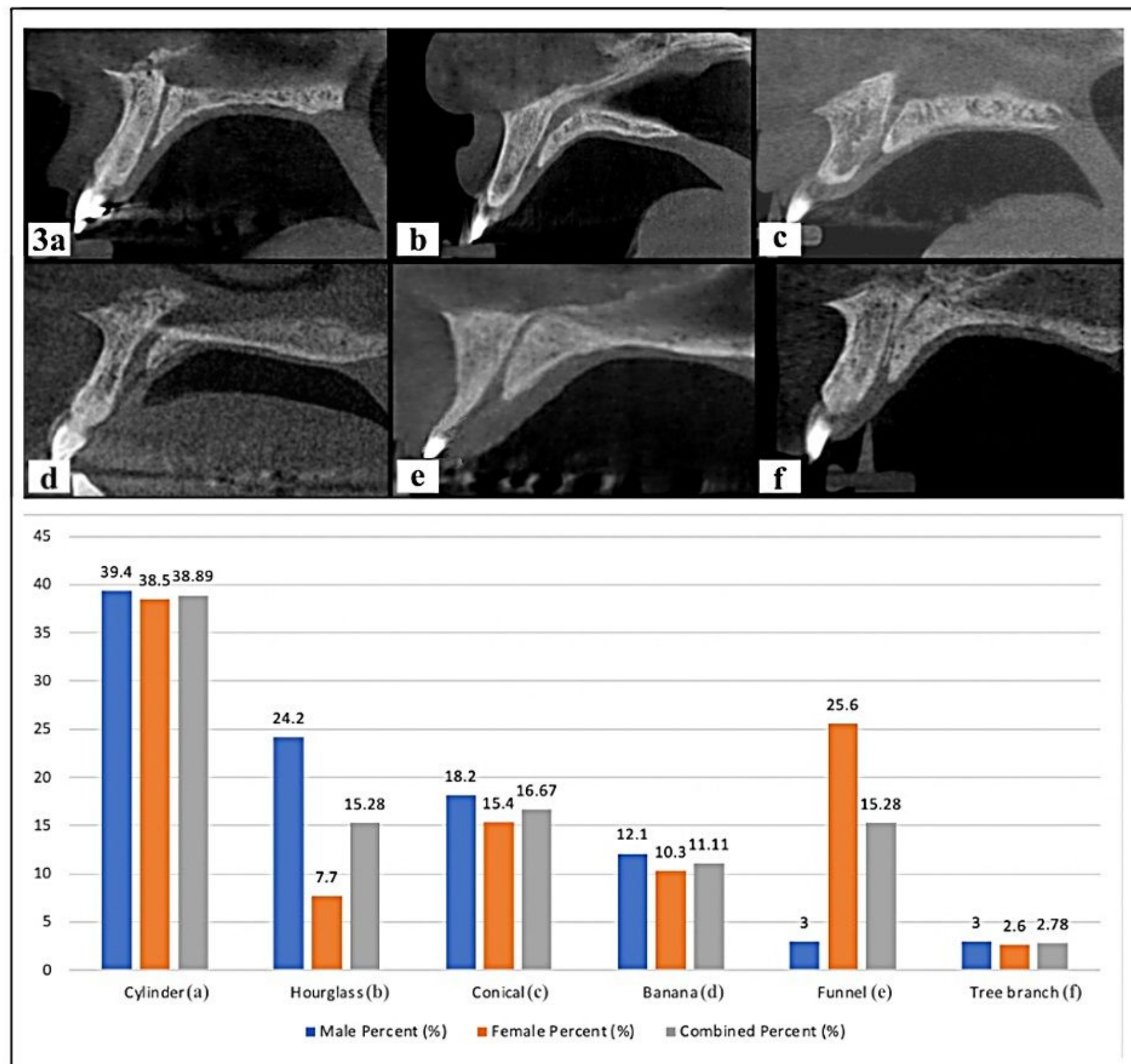

\section{Figure 3}

Representative sagittal CBCT sections of the NPC showing the various shapes encountered in the study with, a clustered column bar chart showing the shape prevalence of the NPC in a sagittal view for both male and female Kenyans. A combined percentage value for both genders is also depicted. 3a: Cylindrical 3b: Hourglass 3c: Conical 3d: Banana 3e: Funnel 3f: Tree-branch 


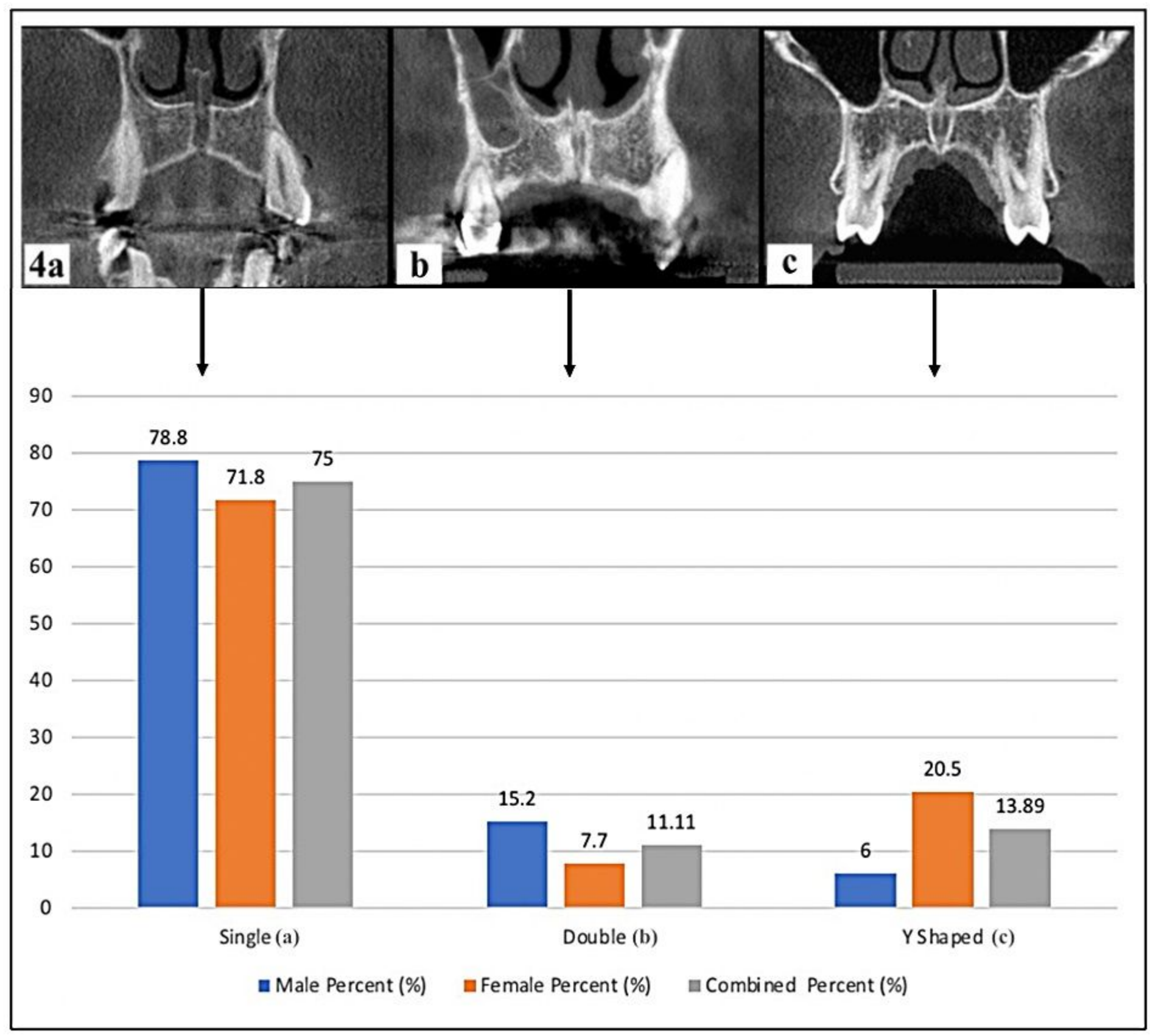

Figure 4

Representative coronal CBCT sections of the NPC showing the various shapes encountered in the study with a clustered column bar chart showing the shape prevalence of the NPC in a coronal view for both male and female Kenyans. A combined percentage value for both genders is also depicted. 4a: Single 4b: Double 4c: Y-shaped 


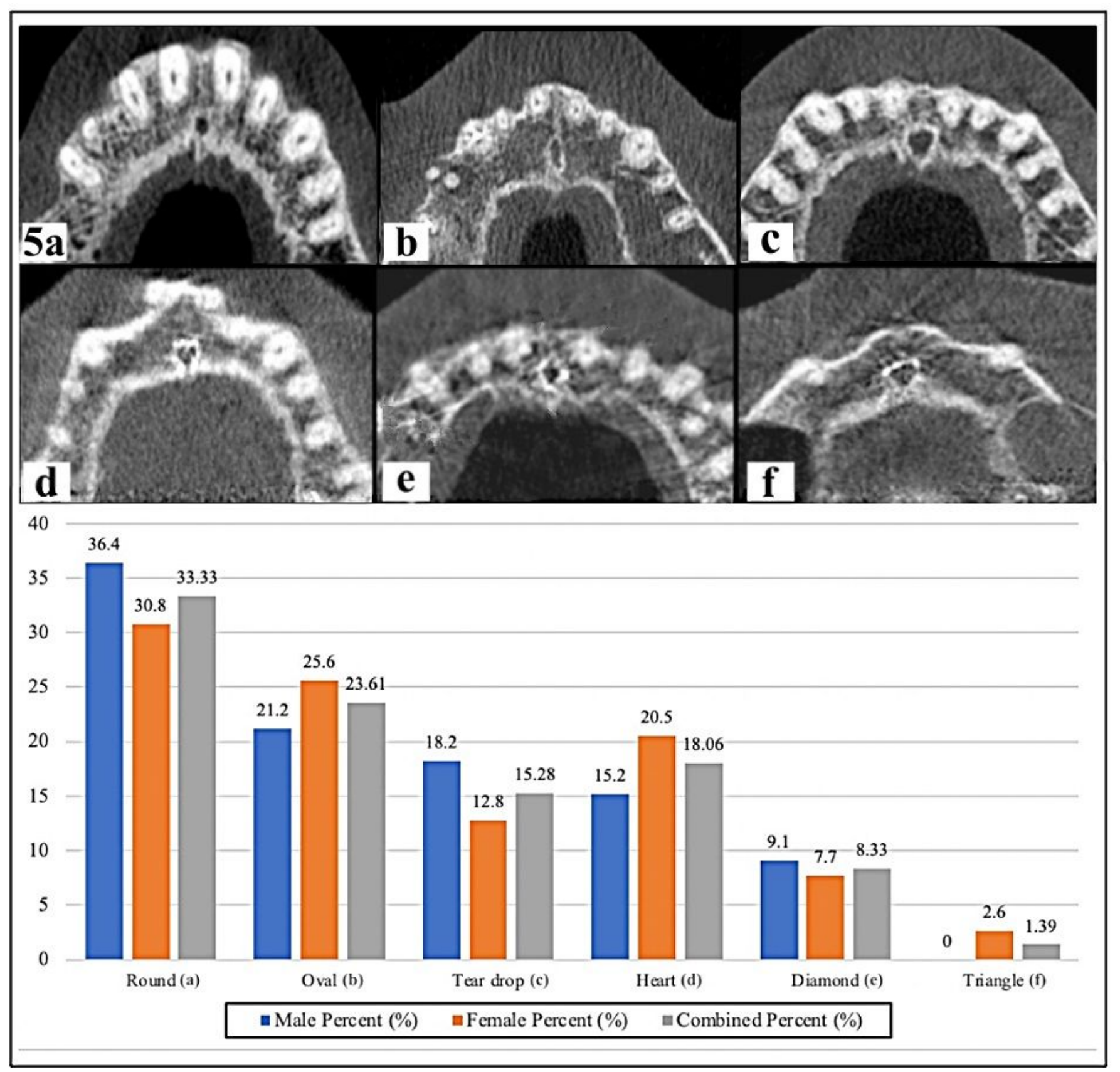

Figure 5

Representative axial CBCT sections of the IF showing the various shapes encountered in the study, with a clustered column bar chart showing the shape prevalence of the IF for both male and female Kenyans. A combined percentage value for both genders is also depicted. 5a: Round 5b: Oval 5c: Teardrop 5d: Heart 5e: Diamond 5f: Triangle 


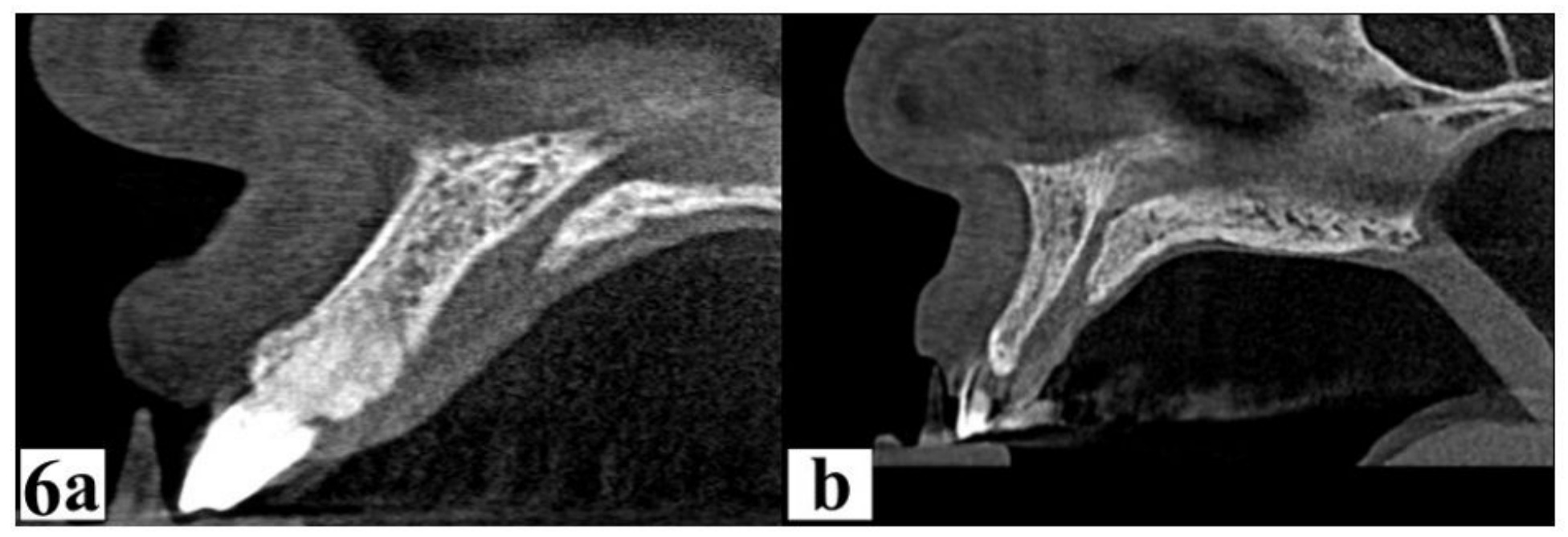

Figure 6

Sagittal CBCT sections of the maxillary bone both the flat (6a) and concave (6b) shapes encountered in the present study 